\title{
Insights into air pollution chemistry and sulphate formation from nitrous acid (HONO) measurements during haze events in Beijing $†$
}

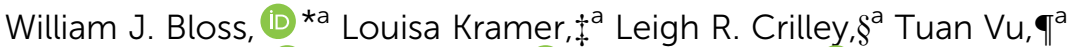 \\ Roy M. Harrison, (D) a Zongbo Shi, (ID a James D. Lee, iD b \\ Freya A. Squires, iD b Lisa K. Whalley, ${ }^{c}$ Eloise Slater, ${ }^{c}$ Robert Woodward- \\ Massey, \|\|$^{c}$ Chunxiang Ye, $\|^{c}$ Dwayne E. Heard, (D) ${ }^{c}$ Shengrui Tong, ${ }^{d}$ \\ Siqi Hou, ${ }^{d}$ Yele Sun, iD e Jingsha $\mathrm{Xu}{ }^{\mathrm{a}}$ Lianfang Wei ${ }^{\mathrm{e}}$ and Pingqing Fu (iD ${ }^{f}$
}

Received 13th August 2020, Accepted 21st September 2020

DOI: $10.1039 / \mathrm{dOfd00100 \textrm {g }}$

Wintertime urban air pollution in many global megacities is characterised by episodic rapid increase in particulate matter concentrations associated with elevated relative humidity so-called haze episodes, which have become characteristic of cities such as Beijing. Atmospheric chemistry within haze combines gas- and condensed-phase chemical processes, leading to the growth in secondary species such as sulphate aerosols. Here, we integrate observations of reactive gas phase species $(\mathrm{HONO}, \mathrm{OH}, \mathrm{NO}$ ) and timeresolved aerosol composition, to explore observational constraints on the mechanisms responsible for sulphate growth during the onset of haze events. We show that HONO abundance is dominated by established fast gas-phase photochemistry, but the consideration of the additional formation potentially associated with condensed-phase oxidation of $\mathrm{S}$ species by aqueous $\mathrm{NO}_{2}$ leading to $\mathrm{NO}_{2}{ }^{-}$production and hence HONO release, improves agreement between observed and calculated gas-phase HONO

\footnotetext{
${ }^{a}$ School of Geography, Earth and Environmental Sciences, University of Birmingham, UK. E-mail: w.j.bloss@ bham.ac.uk

${ }^{b}$ Wolfson Atmospheric Chemistry Laboratories, Department of Chemistry, University of York, UK ${ }^{c}$ School of Chemistry, University of Leeds, UK

${ }^{d}$ Institute of Chemistry, Chinese Academy of Sciences, Beijing, China

${ }^{e}$ State Key Laboratory of Atmospheric Boundary Layer Physics and Atmospheric Chemistry, Institute of Atmospheric Physics, Chinese Academy of Sciences, Beijing, China

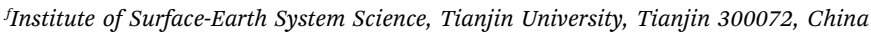

$\dagger$ Electronic supplementary information (ESI) available. See DOI: 10.1039/d0fd00100g

\$ Currently at Ricardo Energy \& Environment, Harwell, Oxfordshire, OX11 0QR, UK.

$\S$ Currently at the Department of Chemistry, York University, Toronto, ON, Canada.

ฯ Currently at the School of Public Health, Imperial College London, UK.

\| Currently at the College of Environmental Sciences and Engineering, Peking University, Beijing, 100871, China.
} 
levels. This conclusion is highly dependent upon aerosol $\mathrm{pH}$, ionic strength and particularly the parameterisation employed for S(IV) oxidation kinetics, for which an upper limit is derived.

\section{Background}

Atmospheric chemical processing leads to the removal of primary pollutants and determines the rate of production of secondary species, including ozone and many components of aerosol particles. Gas-phase processing is driven by a small number of key oxidants, of which the $\mathrm{OH}$ radical is predominant for the majority of species during daytime, including many hydrocarbons and inorganic gas-phase species such as $\mathrm{SO}_{2}$ and $\mathrm{NO}_{2}$. Gas- and condensed-phase oxidation chemistry are coupled across the two phases of aerosol, with a wide range of aqueous oxidants driving the particle phase oxidation of species such as $\mathrm{SO}_{2}$, including $\mathrm{NO}_{2}$ itself.

In many urban areas, particulate matter ( $\mathrm{PM}$, particularly $\mathrm{PM}_{2.5}$ ) is a key regulated air pollutant, whose abundance drives substantial adverse human health impacts, in addition to affecting visibility, radiation transfer and amenity. PM is formed of a complex chemical mixture including both directly emitted (primary) and chemically produced (secondary) components; understanding the relationship between these underpins the accurate identification of direct and indirect PM sources, formulating the most effective and efficient clean air policy.

This challenge is emphasised by the air pollution climatology of Beijing and the North China Plain, where seasonal haze events characterised by episodic $\mathrm{PM}_{2.5}$ excursions to $500 \mu \mathrm{g} \mathrm{m} \mathrm{m}^{-3}$ and above, impact the health and wellbeing of around 400 million people. Sulphate is known to be a major component of the fine size fraction of Beijing haze. The rate of formation of sulphate aerosol from $\mathrm{SO}_{2}$, driven by chemical oxidation, is observed to increase as $\mathrm{PM}_{2.5}$ levels rise, and recent studies into haze formation have found that the rate of production of sulphate aerosol is significantly accelerated in megacities such as Beijing. ${ }^{1} \mathrm{New}$ chemical mechanisms have been proposed, notably including the aqueous phase oxidation of $\mathrm{SO}_{2}$ by $\mathrm{NO}_{2}$, if aerosol $\mathrm{pH}$ is sufficiently high. A by-product of this mechanism is expected to be the production of gas-phase HONO.

Here, we analyse in situ observations collected during the UK-Chinese Air Pollution and Human Health (APHH) campaign in central Beijing during haze episodes in November-December 2016, which constrain the gas-phase production and removal of HONO, and the observed rate of formation of sulphate. We identify constraints from the in situ observations upon potential chemical $\mathrm{SO}_{2}$ oxidation mechanisms contributing to haze formation.

\section{Sulphate aerosol formation in haze}

Secondary $\mathrm{SO}_{4}$ formation is driven by a number of chemical mechanisms. Globally, the dominant process is the gas-phase reaction of $\mathrm{SO}_{2}$ with $\mathrm{OH}$ radicals, leading to the formation of $\mathrm{HSO}_{3}$ intermediates, which rapidly react with $\mathrm{O}_{2}$ forming $\mathrm{SO}_{3}$, which is converted to $\mathrm{H}_{2} \mathrm{SO}_{4}$ through reaction with water vapour. The recently characterized rapid reaction between $\mathrm{SO}_{2}$ and criegee intermediates formed through alkene ozonolysis,${ }^{2}$ is unlikely to significantly impact boundary layer $\mathrm{SO}_{2}$ oxidation due to the rapid removal of criegee intermediates by water 
vapour and the water vapour dimer. ${ }^{3,4} \mathrm{SO}_{2}$ may also partition to aqueous aerosol particles, where a series of equilibria partition between $\mathrm{SO}_{2} \cdot \mathrm{H}_{2} \mathrm{O}$ (at low $\mathrm{pH}$ ), $\mathrm{HSO}_{3}{ }^{-}$(pH 2-7) or $\mathrm{SO}_{3}{ }^{2-}$ under basic conditions. In the aqueous phase, $\mathrm{SO}_{2}$ processing is driven by $\mathrm{H}_{2} \mathrm{O}_{2}$ (when $\mathrm{pH}$ is near neutral) and $\mathrm{O}_{3}$ (of increasing importance under more acidic conditions). Transition metals (Fe, $\mathrm{Mn}$ ) can also catalyse $\mathrm{O}_{2}$ reactions leading to condensed phase sulphate formation. During the onset of haze events, sulphate formation rates of the order of tens of $\mu \mathrm{g}$ per $\mathrm{m}^{3}$ per hour are observed. ${ }^{1}$ Very recently, Wang et al. ${ }^{5}$ reported the potential for HONOmediated $\mathrm{SO}_{2}$-to-SO $\mathrm{S}_{4}$ oxidation in Beijing cloud/fog, with associated $\mathrm{N}_{2} \mathrm{O}$ formation.

However, current air quality models fail to reproduce elevated sulphate levels in winter haze. Several mechanisms for S(Iv) oxidation are still under consideration to account for the underestimation of sulphate concentration between model simulations and field observations, including reactive nitrogen chemistry involving the oxidation of $\mathrm{S}(\mathrm{Iv})$ by $\mathrm{NO}_{2},{ }^{6-10}$ underestimation of the transient metals catalyzed pathway, ${ }^{\mathbf{1 1 2} 12}$ the possible oxidation on the surface of acid droplets by $\mathrm{O}_{2},{ }^{13}$ or the otherwise dominant role of $\mathrm{S}(\mathrm{Iv})+\mathrm{H}_{2} \mathrm{O}_{2}$ pathway. ${ }^{14}$ Although these pathways can improve the agreement between sulphate simulation and measurement, there remains a lack of independent constraints on modelling results, especially the potentially dominant role of the $\mathrm{NO}_{2}-\mathrm{S}$ reaction. A tagging methodology with triple oxygen isotopes has been applied as a proxy to constrain the relative contributions of the individual oxidation pathways of $\mathrm{S}(\mathrm{Iv}),{ }^{12,15}$ with results showing that the $\mathrm{NO}_{2}-\mathrm{S}$ reaction is highly dependent on $\mathrm{pH}$ and dominant under high-pH conditions, however, a very substantial uncertainty resulted from the assumed activity coefficient between the aerosol liquid phase ionic strength and parameterisation of the kinetic reaction rate.

The reaction between $\mathrm{NO}_{2}$, partitioned into the aqueous phase, with $\mathrm{HSO}_{3}{ }^{-}$ remains a potentially dominant driver of sulphate formation under haze conditions, forming $\mathrm{SO}_{4}{ }^{2-}$ at rates of $1-7 \mu \mathrm{g} \mathrm{m} \mathrm{m}^{-3} \mathrm{~h}^{-1}: \mathbf{6 , 8}$

$$
2 \mathrm{NO}_{2(\mathrm{aq})}+\mathrm{HSO}_{3(\mathrm{aq})}{ }^{-}+\mathrm{H}_{2} \mathrm{O}_{(\mathrm{aq})} \rightarrow 3 \mathrm{H}_{(\mathrm{aq})}{ }^{+}+2 \mathrm{NO}_{2(\mathrm{aq})}{ }^{-}+\mathrm{SO}_{4(\mathrm{aq})}{ }^{2-}
$$

This is in contrast to tropospheric cloud processing of sulphur species, which is dominated by the $\mathrm{H}_{2} \mathrm{O}_{2}$ and $\mathrm{O}_{3}$ reactions, with $\mathrm{NO}_{2}$ processing relatively unimportant. ${ }^{16}$ The mechanism has the potential to drive a positive feedback in haze formation, where increased sulphate production leads to increased aerosol water and hence $\mathrm{SO}_{2}$ uptake and oxidation, under conditions of high $\mathrm{NO}_{2} \cdot{ }^{6} \mathrm{Of}$ particular note here, the condensed phase nitrite is expected to be released from acidic aerosol to the atmosphere as HONO. ${ }^{8}$

The ionic composition of the aqueous aerosol is critically important in calculating the importance of the $\mathrm{NO}_{2}$ mechanism - ionic strength (which impacts the rate constants for the $\mathrm{S}(\mathrm{vI})$ oxidation reactions) and aerosol $\mathrm{pH}$. Elevated $\mathrm{pH}$ enhances $\mathrm{SO}_{2}$ solubility (higher effective Henry's law constant); consequently chemical factors to maintain elevated aerosol $\mathrm{pH}(5-7)$ are required, and have been attributed to high levels of ammonia emissions/ammonium in the North China Plain, ${ }^{6,8}$ However, subsequent analyses have concluded that the highest observed $\mathrm{NH}_{3}$ levels are insufficient to raise $\mathrm{pH}$ levels above 4.5 under haze conditions, and hence it is unlikely that $\mathrm{NO}_{2}$-mediated oxidation of $\mathrm{SO}_{2}$ is 
a major sulphate formation route in Beijing haze, compared with $\mathrm{O}_{3}$ and transition-metal mediated oxidation. ${ }^{11}$

\section{Boundary layer HONO photochemistry}

The basic gas-phase chemistry of HONO combines formation through the homogenous termolecular $\mathrm{OH}+\mathrm{NO}$ reaction (R2), and reaction of $\mathrm{HONO}$ with $\mathrm{OH}$ (R3) and relatively rapid solar photolysis (R4), where the photolysis frequency (1.7 $\times 10^{-3} \mathrm{~s}^{-1}$ at $\mathrm{SZA}=40^{\circ}$ ) corresponds to a typical mid-latitude local solar noon lifetime of around $10 \mathrm{~min}$.

$$
\begin{gathered}
\mathrm{OH}+\mathrm{NO}+\mathrm{M} \rightarrow \mathrm{HONO}+\mathrm{M} \\
\mathrm{HONO}+\mathrm{OH} \rightarrow \mathrm{H}_{2} \mathrm{O}+\mathrm{NO}_{2} \\
\mathrm{HONO}+h \nu \rightarrow \mathrm{OH}+\mathrm{NO}
\end{gathered}
$$

HONO photolysis (R4) is an important, and frequently the dominant, source of $\mathrm{OH}$ radicals in the continental boundary layer, accounting for $40 \%$ of $\mathrm{OH}$ formation in central London, ${ }^{17}$ over $80 \%$ of $\mathrm{OH}$ production at a rural site in Colorado, ${ }^{18}$ and most recently an average of $83 \%$ of $\mathrm{OH}$ production in wintertime Beijing $^{19}$ - hence, HONO abundance and formation mechanisms are tightly coupled to the production of $\mathrm{OH}$ and rate of in situ gas-phase oxidation for many atmospheric pollutants.

HONO levels may be predicted by reactions (R2)-(R4), assuming a photochemical steady state (see below), which may then be compared with observed concentrations to ascertain the presence of additional HONO sources. This exercise has been undertaken a number of times, leading to a range of additional HONO sources being identified - which are frequently significantly larger than the homogeneous $\mathrm{OH}+\mathrm{NO}$ reaction. Examples include source strengths exceeding reaction (R2) by factor 13 in a European forest, ${ }^{20} 30$ at Hyytiälä ${ }^{21}$ and a factor of 19 in rural China. ${ }^{22}$ In performing such analyses, it is important to note the timescales for HONO are rather longer than those of $\mathrm{OH}$, hence analysis in highly spatially heterogeneous environments can be challenging as noted by Lee et $a l .{ }^{23}$ and Crilley et al. ${ }^{24}$

In general terms, such sources may be combined as an additional source term, $S_{\text {HONO}}$, if HONO may be placed into the steady state:

$$
\begin{gathered}
S_{\mathrm{HONO}} \rightarrow \mathrm{HONO} \\
\mathrm{d}[\mathrm{HONO}] / \mathrm{d} t=k_{2}[\mathrm{OH}][\mathrm{NO}]+S_{\mathrm{HONO}}-k_{3}[\mathrm{OH}][\mathrm{HONO}]-j_{4}[\mathrm{HONO}]
\end{gathered}
$$

A number of mechanisms for further atmospheric HONO emission and production have been suggested. Direct emission sources include vehicle exhausts (with HONO emissions equivalent to $1.24 \%$, and $0.85 \%$ of $\mathrm{NO}_{x}$ emissions recently derived for the Hong Kong and UK vehicle fleets, respectively), ${ }^{25,26}$ biocrusts, ${ }^{27}$ and microbial soil emissions. ${ }^{28}$ Heterogeneous HONO sources include dark reactions between $\mathrm{NO}_{2}$ and water (e.g. Finlayson-Pitts et al. ${ }^{29}$ ) on ground and aerosol surfaces, photolysis of nitrophenols, and photoenhanced conversion of $\mathrm{NO}_{2}$ to $\mathrm{HONO}$ in the presence of organic chromophores. ${ }^{30}$ 
Substantial work has been undertaken and the reader is directed to the reviews of Kleffman ${ }^{31}$ and Spataro and Ianniello. ${ }^{32}$

The UK-Chinese Air Pollution and Human Health - Beijing experiment (APHH-Beijing), was funded by the UK Natural Environment Research Council and the National Science Foundation of China. APHH-Beijing brought together well over 100 instruments to study boundary layer atmospheric composition and haze formation at the Institute of Atmospheric Physics (IAP), Chinese Academy of Sciences in central Beijing in November-December 2016 and spring-summer 2017.

Here, we combine co-located measurements from the APHH study, alongside numerical model calculations, to explore potential constraints on the sulphate formation mechanisms under haze conditions in Beijing. We compare the abundance of HONO with potentially determinant parameters including PM, meteorological factors and aerosol composition (including $\mathrm{SO}_{4}$ ). We calculate the HONO concentrations which would be predicted in ambient air from established gas-phase chemistry (reactions (2)-(4)), and the rate of HONO formation from the aerosol-mediated $\mathrm{NO}_{2} / \mathrm{SO}_{2}$ oxidation process (reaction (1)). We compare predicted HONO levels with those observed, and discuss the quantitative agreement in the context of different approaches to parameterising the $\mathrm{NO}_{2}$-enhanced $\mathrm{SO}_{2}$ oxidation kinetics. Implications for air quality are discussed.

\section{APHH-Beijing measurements}

Measurements were acquired during the APHH-Beijing winter experiment, conducted from 10 November-10 December 2016 at the Institute of Atmospheric Physics (IAP), Chinese Academy of Sciences in central Beijing $39^{\circ} 58^{\prime} 33^{\prime \prime} \mathrm{N}$, $116^{\circ} 22^{\prime} 41^{\prime \prime} \mathrm{E}$, between the third and fourth North ring roads. The site is in a residential area, with a number of substantial highways $c a .150 \mathrm{~m}$ away to the south, north and west. On the site itself, an open grassed area is surrounded by 23 storey buildings, with larger structures (residential blocks) some 200-300 m away. A canal runs past the north perimeter of the site, with a park (including conifer pine trees) further to the west. Given recent work to relocate industry from central Beijing, the dominant local emission sources are anticipated to be traffic and domestic activities, with possible contributions from light industry, for $\mathrm{NO}_{x}$. For $\mathrm{SO}_{2}$, sources are anticipated to be regional, industry and power/heatingrelated combustion (including coal) around the city periphery. For full details of the site, instruments and campaign overview, including a detailed meteorological timeseries, see Shi et $a .^{33}$

$\mathrm{OH}$ radicals were measured via laser-induced fluorescence, using the fluorescence assay by gas expansion (FAGE) methodology. Full details of the instrument operation and calibration are given in Slater et al. ${ }^{19}$ NO was measured using chemiluminescence employing a Thermo TE42i $\mathrm{NO}_{x}$ monitor, calibrated to an NPL $\alpha$-standard. Photolysis frequencies $\left(j_{\text {HONO }}\right)$ were measured at ground level using a calibrated spectral radiometer. HONO was measured using the LOPAP (Long Path Optical Absorption Photometry) approach. The LOPAP is a wet chemical technique and has been described in detail in Heland et al. ${ }^{34}$ and Kleffmann et al. ${ }^{35}$ Briefly, a stripping coil entrains gas-phase HONO into an acidic solution where it is derivatized into an azo dye, detected by long path absorption at $550 \mathrm{~nm}$, and calibrated against an aqueous phase nitrite standard. The LOPAP 
was operated and calibrated according to the standard procedures described in Kleffmann and Wiesen. ${ }^{36}$ A detailed account of the APHH-Beijing HONO dataset, including an intercomparison of HONO measurements by LOPAP, broadband cavity absorption spectrometry, chemical ionisation mass spectrometry and proton transfer reaction mass spectrometry is given in Crilley et al. ${ }^{37}$ All data were acquired at ground level (inlet heights $=5 \mathrm{~m}$ ).

Aerosol data for sulphate mass concentration were taken from AMS (aerosol mass spectrometer) measurements; these therefore correspond to the fine fraction $\left(\mathrm{PM}_{1}\right)$ of the particulate matter present. The sulphate concentrations determined by AMS data were compared with the results obtained by 24 hour highvolume $\mathrm{PM}_{2.5}$ filter samples collected at the IAP site during December 2016, and analysed in the laboratory by ion chromatography. ${ }^{38}$ The two datasets were found to be within $20 \%$ of each other $\left(r^{2}=0.97\right)$ and the AMS data were used without further adjustment. $\mathrm{PM}_{2.5}$ mass concentrations were derived by TEOMFDMS, and were recorded at the top of a two-storey building (about $10 \mathrm{~m}$ above ground level). Data were averaged to hourly mean mixing ratios using in situ temperature and pressure measurements. The period 2-10 December was selected as this encompassed several periods of haze, with rapid and dramatic $\mathrm{PM}_{2.5}$ growth reaching nearly $500 \mu \mathrm{g} \mathrm{m}^{-3}$ (haze periods typically identified as $\mathrm{PM}_{2.5}>75 \mu \mathrm{g} \mathrm{m}^{-3}$ ), and maximised overlap between the operational periods of the various instruments used - during this date range, $65 \%$ of the necessary

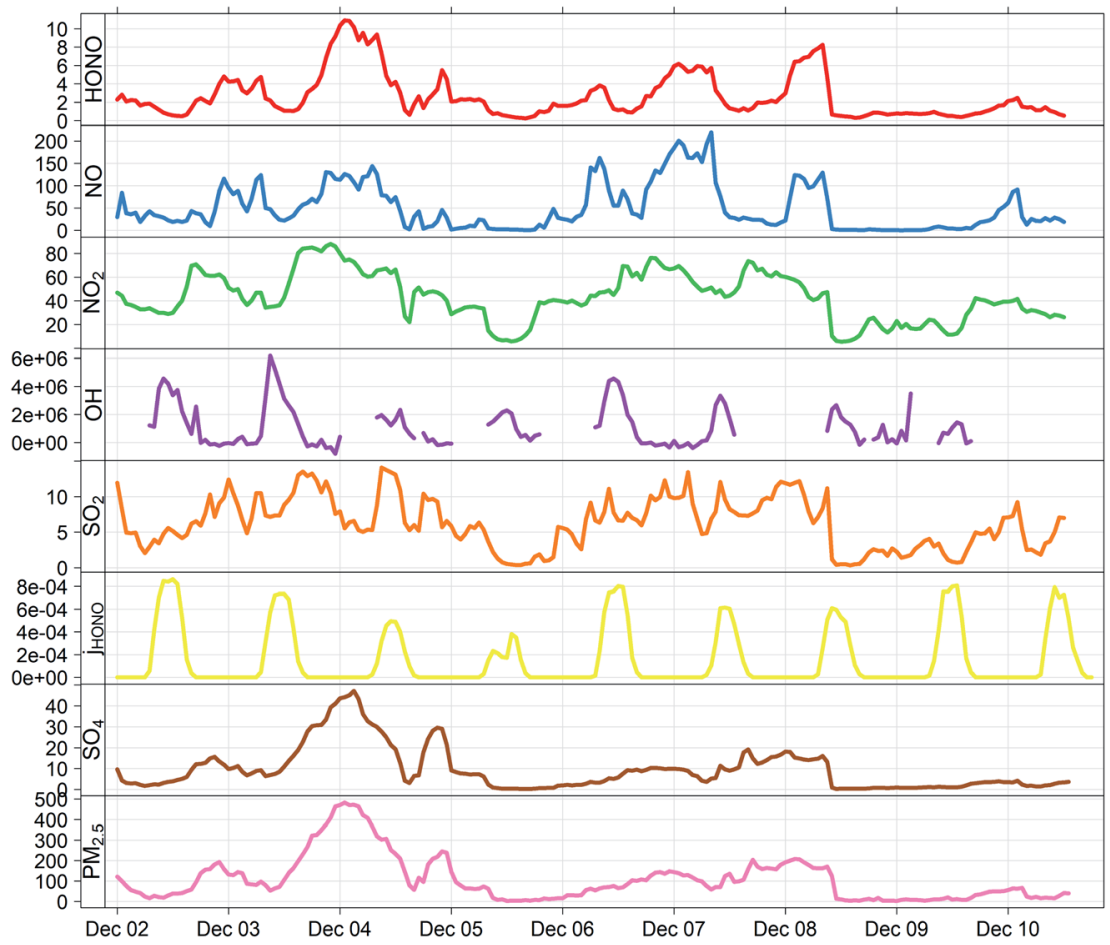

Fig. 1 Measured timeseries for $\mathrm{HONO}(\mathrm{ppb}), \mathrm{NO}(\mathrm{ppb}), \mathrm{NO}_{2}(\mathrm{ppb}), \mathrm{OH}\left(\operatorname{molec~} \mathrm{cm}^{-3}\right), \mathrm{SO}_{2}$ $(\mathrm{ppb}), j_{\text {HONO }}\left(\mathrm{s}^{-1}\right), \mathrm{SO}_{4}\left(\mathrm{AMS} ; \mu \mathrm{g} \mathrm{m}^{-3}\right.$ ) and $\mathrm{PM}_{2.5}\left(\mathrm{TEOM}\right.$ FDMS; $\mu \mathrm{g} \mathrm{m}^{-3}$ ) at the IAP tower site during the APHH Beijing winter campaign, 2016. 
measurements were present (see Fig. 1), limited primarily by the $\mathrm{OH}$ and HONO datasets. Conditions during this period were typical of the wider APHH winter campaign (see Shi et al. ${ }^{33}$ for climatological details).

\section{Analysis of in situ observations}

Fig. 1 shows the characteristic pattern of haze event onset observed previously, and associated with increases in many air pollutant species and intermediates; daily mean mixing ratios/concentrations are given in ESI Tables ST1 and ST2. $\dagger$ There is a positive correlation between HONO and sulphate abundance, indicating commonality in their mechanisms of formation/removal. In general, HONO abundance is frequently closely coupled with that of $\mathrm{NO}_{2}$ (through heterogeneous $\mathrm{NO}_{2}$-to-HONO conversion chemistry, and/or co-emission of both species), and variations in the $\mathrm{HONO} / \mathrm{NO}_{2}$ ratio can be used to characterise this relationship. We find HONO levels are correlated with the abundance of $\mathrm{PM}_{2.5}$ $\left(r^{2}=0.67\right)$ and of aerosol sulphate $\left(r^{2}=0.59\right)$, but the $\mathrm{HONO} / \mathrm{NO}_{2}$ ratio is much less strongly related to $\mathrm{PM}_{2.5}$ abundance $\left(r^{2}=0.27\right)$, indicating that the interaction between particulate matter and HONO may be more strongly related to sulphate chemistry, than $\mathrm{NO}_{2}$-to-HONO heterogeneous conversion. The HONO$\mathrm{SO}_{4}$ relationship does not show any dependence upon $\mathrm{SO}_{2}$, but higher levels of both species are strongly associated with higher RH (Fig. 2), indicating a potential association with aqueous content, such as the condensed phase $\mathrm{SO}_{2}$ oxidation mechanisms outlined above.

The measurement data coverage during the APHH-Beijing campaign at IAP provides direct constraints on the major (gas-phase, photochemical) processes forming and removing ambient nitrous acid, including measurements of concentrations of $\mathrm{OH}, \mathrm{NO}, \mathrm{HONO}$ and meteorological/photolysis parameters. We averaged data to an hourly time resolution, and evaluated the consecutive changes in concentration of HONO (i.e. $\mathrm{d}[\mathrm{HONO}] / \mathrm{d} t$, defined simply as the difference in consecutive hourly mean measurements of HONO abundance), and
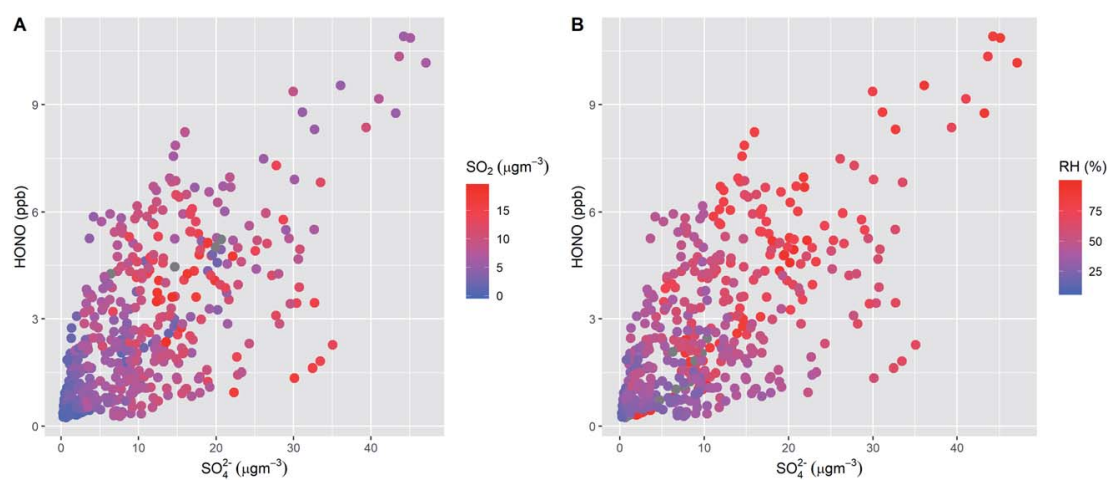

Fig. 2 Relationship between $\mathrm{HONO}$ and $\mathrm{SO}_{4}$ concentrations, coloured by $\mathrm{SO}_{2}$ abundance (panel A) and by relative humidity $(\mathrm{RH}$, panel $\mathrm{B})$, during the 2-10 December focus period. The data show the limited impact of $\mathrm{SO}_{2}$, but the highest levels of both $\mathrm{HONO}$ and $\mathrm{SO}_{4}$ are associated with elevated humidity. 
rate of the chemical reactions forming and removing HONO over the equivalent time periods (E1).

Fig. 3 shows the derived timeseries for $\mathrm{d}[\mathrm{HONO}] / \mathrm{d} t$, and the individual components of HONO formation and removal, focusing upon the case study period of 2-10 December. The dominance of the conventional gas-phase chemistry is apparent, with HONO formation dominated by the $\mathrm{OH}+\mathrm{NO}$ reaction, and removal by photolysis, with a small to negligible contribution from the $\mathrm{OH}+$ HONO reaction.

Discounting potential additional sources of $\mathrm{HONO}$ (i.e., assuming $S_{\mathrm{HONO}}=0$ ), we can calculate the HONO abundance that would be predicted assuming the steady state applies. We limit the analysis to daylight only (here, hourly-averaged data where the HONO lifetime is less than $60 \mathrm{~min}$ ), corresponding to $j_{\mathrm{HONO}}>2.78$ $\times 10^{-4} \mathrm{~s}^{-1}$, and where all measurements are available (HONO, OH, NO, $\mathrm{SO}_{2}$, photolysis parameters, aerosol composition) - this condition reduces the available data to 44 hourly averages, $23 \%$ of the total over the focus period (the principal reduction $v s$. the coverage noted above arises due to the restriction to daylight hours). The predicted HONO concentration is compared with that observed in Fig. 4. The PSS-calculated (red triangles) and observed (blue circles) HONO mixing ratios are in relatively good agreement, indicating limited immediate need for additional production terms. A clearer picture is obtained from the regression analysis (Fig. 5), comparing the PSS-calculated and observed HONO mixing ratios (red triangles). While the data are scattered, overall the observed and calculated mixing ratios are similar in overall magnitude, without evidence for orders-of-magnitude error. Regression analysis derives gradient and intercept values of $0.90 \pm 0.38$ and $(0.59 \pm 0.84)$ ppb respectively $( \pm 2 \sigma)$, with an $r^{2}$ coefficient of 0.35 . HONO measurements performed by multiple independent techniques during the APHH-Beijing study have been compared by Crilley et al. ${ }^{37}$ who showed that the LOPAP-derived HONO data had a detection limit of around 35 ppt (i.e. very much smaller than the scatter of the observations), and that all instruments (using different techniques) were extremely well correlated with each other $(r>0.97)$, but with variations in slope (i.e. absolute accuracy) of 0.61-0.88.

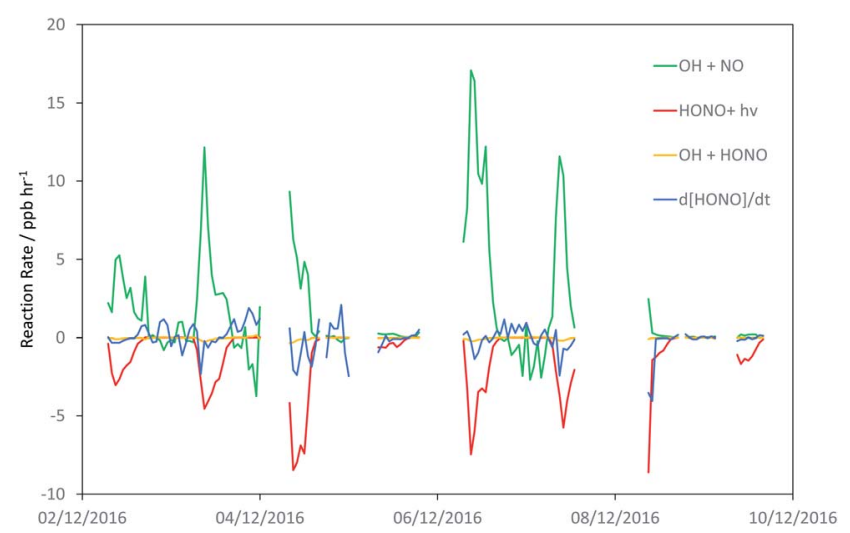

Fig. 3 Timeseries of the observationally-derived components of in situ HONO formation and destruction: reactions of $\mathrm{OH}+\mathrm{NO}$ (R2), $\mathrm{OH}+\mathrm{HONO}(\mathrm{R} 3), \mathrm{HONO}+h \nu$ (R4), plus the observed rate of change of $\mathrm{HONO}, \mathrm{d}[\mathrm{HONO}] / \mathrm{d} t$. 


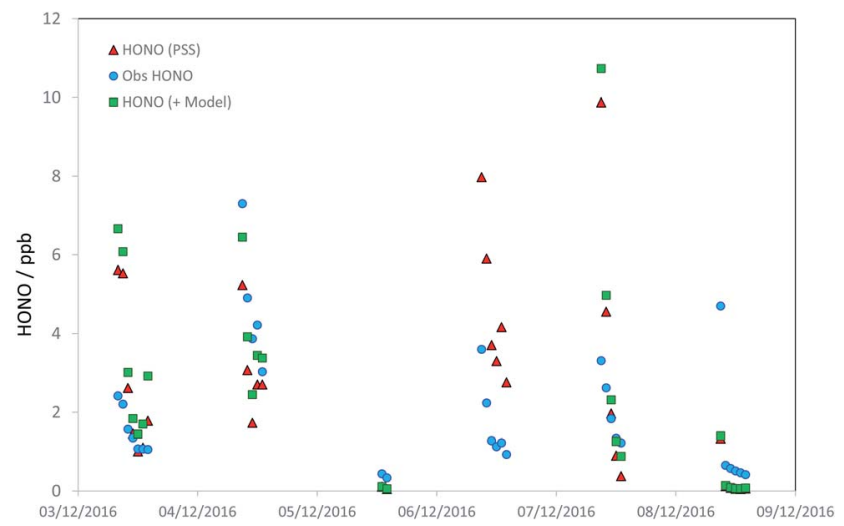

Fig. 4 Timeseries of observed daytime HONO mixing ratios (blue circles), steady state calculated HONO mixing ratios - HONO PSS, as derived from application of eqn (E1) (red triangles) and model calculated HONO (see text; green squares).

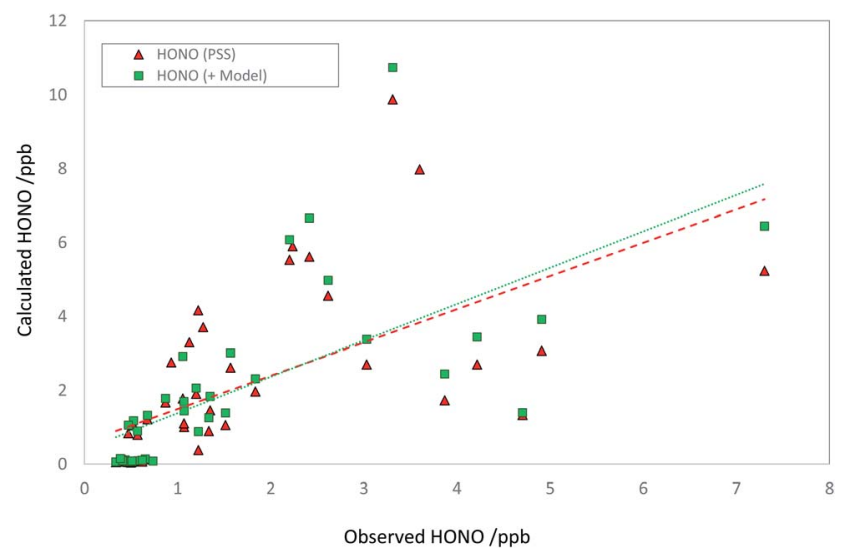

Fig. 5 Correlation between observed $\mathrm{HONO}$ and PSS-predicted mixing ratios (red triangles), regression line (red dashes), and model calculated HONO levels (see text; green squares) and associated regression (green dots).

Therefore the scatter in the observed data in Fig. 4 does not reflect measurement precision (although the observations may collectively be biased high or low, depending on the absolute accuracy), and rather reflects changes in the actual observed concentrations, in turn reflecting variations in the atmospheric source and sink-terms as integrated over the HONO lifetime.

The data can also be analysed to quantify HONO formation (or removal) mechanisms not accounted for by the basic chemistry (reactions (R2)-(R4)) through application of (E1) alongside the observed d[HONO]/d $t$ to derive $S_{\text {HONO, }}$ however the inferred net source for HONO, $S_{\text {HONO }}$, is very scattered and displays no correlation with $\mathrm{SO}_{2}$ or $\mathrm{SO}_{4}$ abundance $\left(r^{2}=0.04\right.$ and 0.02 respectively), or with the $\mathrm{SO}_{2}$-normalised rate of $\mathrm{SO}_{4}$ formation $\left(r^{2}=0.05\right)$ - not shown. A crude estimation of the rate of formation of $\mathrm{HONO}$ (technically, $\mathrm{NO}_{2}{ }^{-}$) which would be associated with $\mathrm{SO}_{2}$ oxidation $\left(P_{\text {sulphate }}\right)$ can be obtained from the observed rate of 
formation of sulphate, $\mathrm{d}\left[\mathrm{SO}_{4}\right] / \mathrm{d} t$, multiplied by a factor of 2 for the stoichiometry of $\mathrm{NO}_{2}{ }^{-}$formation:

$$
P_{\text {sulphate }}=2 \times \mathrm{d}\left[\mathrm{SO}_{4}\right] / \mathrm{d} t
$$

Critically, in addition to disregarding other (non- $\mathrm{NO}_{2}$-mediated) mechanisms for $\mathrm{SO}_{2}$ oxidation, this estimate for $\mathrm{HONO}$ formation associated with $\mathrm{SO}_{4}$ production neglects the effect of dynamics, i.e. advection of more (or less) polluted airmasses across the study site - leading to negative as well as positive values (Fig. S1 $\dagger$ ). Nonetheless it is instructive to compare the resulting daytime

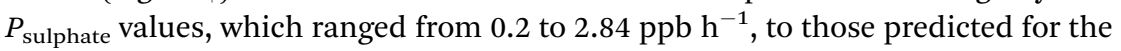
$\mathrm{OH}+\mathrm{NO}$ reaction (Fig. 3 ) - the $P_{\text {sulphate }}$ values are nearly one order of magnitude smaller (and likely significant overestimates during periods of haze growth, due to pollution advection).

\section{Model quantification of $\mathrm{SO}_{2}$ oxidation pathways}

To more comprehensively quantify the relative importance of different $\mathrm{SO}_{2}$ oxidation mechanisms and the interaction with HONO formation, a zerodimensional numerical model constrained to the observed conditions was used to calculate the gas- and condensed-phase $\mathrm{SO}_{2}$ oxidation rates for the focus period. The model framework involved a series of processes, consisting of gasphase reaction of $\mathrm{SO}_{2}$ with $\mathrm{OH}$, absorption equilibria of gaseous species, ionization, aqueous phase chemical reactions of $\mathrm{S}(\mathrm{IV})$, and the kinetics of mass transport. The model assumed that air infuses into the aerosol water and then participates in chemical reactions. The condensed-phase oxidation of S(Iv) by $\mathrm{H}_{2} \mathrm{O}_{2}, \mathrm{O}_{3}$, oxygen catalyzed by $\mathrm{Fe}^{3+} / \mathrm{Mn}^{2+}$ or $\mathrm{NO}_{2}$ in the aerosol water were explicitly represented. The influence of primary sulphate emission and regional transportation were disregarded - the focus is on in situ chemical production only. The kinetics of sulphate formation and its dependence on ionic strength of aerosol water were implemented following Cheng et al. ${ }^{6}$ and He et al. ${ }^{15}$ Concentrations of $\mathrm{Fe}^{3+}$ and $\mathrm{Mn}^{2+}$ were $\mathrm{pH}$-dependent and followed the precipitation equilibria of $\mathrm{Fe}(\mathrm{OH})_{3}$ and $\mathrm{Mn}(\mathrm{OH})_{2}$.

The Nested Air Quality Prediction Model System (NAQPMS) developed by the Institute of Atmospheric Physics, Chinese Academy of Sciences (IAP/CAS) was adopted to simulate hourly concentrations of $\mathrm{OH}$ free radicals and $\mathrm{H}_{2} \mathrm{O}_{2}$ during the field campaign. ${ }^{39}$ NAQPMS incorporated the Carbon Bond Mechanism version $\mathrm{Z}(\mathrm{CBM}-\mathrm{Z})^{40}$ to simulate gas-phase reactions. The modeled $\mathrm{OH}$ and $\mathrm{H}_{2} \mathrm{O}_{2}$ concentrations were used in the estimation of sulphate formation from the gasphase reaction of $\mathrm{OH}$ with $\mathrm{SO}_{2}$ and the aqueous-phase reaction of $\mathrm{H}_{2} \mathrm{O}_{2}$ with $\mathrm{HSO}_{3}{ }^{-}$, and (in the case of $\mathrm{OH}$ ) to evaluate the model oxidant field calculation. The observed aerosol composition, gaseous $\mathrm{NH}_{3}$ and meteorological conditions were input into the ISORROPIA-II thermodynamic equilibrium model ${ }^{41}$ to estimate the aerosol water content (AWC), aerosol water $\mathrm{pH}$, and ionic strength (Table ST2 $\dagger$ ). The model was run in forward mode and predicted the phase partitioning of a $\mathrm{K}^{+} / \mathrm{Ca}^{2+} / \mathrm{Mg}^{2+} / \mathrm{NH}_{4}{ }^{+} / \mathrm{Na}^{+} / \mathrm{SO}_{4}{ }^{2-} / \mathrm{NO}_{3}{ }^{-} / \mathrm{Cl}^{-} / \mathrm{H}_{2} \mathrm{O}$ in thermodynamic equilibrium with gas-phase precursors.

By way of validation, the modelled and observed $\mathrm{OH}$ levels ${ }^{19}$ as a sensitive test of the integrated NAQPMS oxidation (VOC, $\mathrm{NO}_{x}$ and $\mathrm{O}_{3}$ chemistry), are compared 
in Fig. S2. $\uparrow$ Overall, agreement was good, with the model showing good skill in reproducing the diurnal behaviour of $\mathrm{OH}$. The absolute modelled $\mathrm{OH}$ levels were within $15 \%$ of those observed on 4 of the 6 days considered, but exceeded those observed (by up to a factor of 2) on the remaining 2 days (interestingly, those characterised by the lowest NO levels).

The modelled rate of formation of $\mathrm{SO}_{4}$ was determined for $\mathrm{OH}$ (gas phase), $\mathrm{H}_{2} \mathrm{O}_{2}, \mathrm{O}_{3}$, transition metals (Fe, Mn catalysed $\mathrm{O}_{2}$ reaction) and $\mathrm{NO}_{2}$ driven processes. Ionic strength is a key factor in such calculations: sulphate production rates were calculated for three cases: (A) neglecting the impact of ionic strength; (B) considering the impact of ionic strength upon the solubility of $\mathrm{SO}_{2}$ and the dissociation of $\mathrm{H}_{2} \mathrm{SO}_{3}$ (ref. 42) and upon the kinetics of the $\mathrm{H}_{2} \mathrm{O}_{2}, \mathrm{O}_{3}$ and transition metal reactions; and (C) also considering the impact of ionic strength upon the rate constant for the $\mathrm{NO}_{2}+\mathrm{S}$ (Iv) reaction, following the parameterisations of Cheng et al. ${ }^{6}$ We compared these approaches as there is a lack of experimental data for the influence of ionic strength upon the $\mathrm{NO}_{2}-\mathrm{S}$ reaction, and the calculated aerosol ionic strength during severe haze events reaches $60 \mathrm{M}$ (when $\mathrm{RH}>$ $40 \%$ and $\mathrm{PM}_{2.5}>75 \mu \mathrm{g} \mathrm{m}^{-3}$ ) hence extrapolations from the conditions of dilute solutions may not be warranted.

Discounting ionic strength effects (i.e., case A), $\mathrm{SO}_{4}$ formation averaged over the whole 12 November-10 December 2016 campaign period is found to be dominated by gas-phase $\mathrm{OH}$ chemistry ( $51 \%$ ), followed by condensed phase $\mathrm{H}_{2} \mathrm{O}_{2}$ and transition metal reactions, with $\mathrm{NO}_{2}$ reaction responsible for $1.6 \%$. Considering ionic strength effects other than $\mathrm{NO}_{2}$ kinetics (case $\mathrm{B}$ ), oxidation of $\mathrm{SO}_{2}(\mathrm{~g}$ ) by $\mathrm{OH}$ drives $81 \%$ of $\mathrm{SO}_{4}$ formation, with $18 \%$ arising from $\mathrm{H}_{2} \mathrm{O}_{2}$ and $0.6 \%$ for reaction with $\mathrm{NO}_{2}$ - however the average and maximum rates of $\mathrm{SO}_{4}$ formation calculated were 0.036 and $0.29 \mu \mathrm{g} \mathrm{m}^{-3} \mathrm{~h}^{-1}$ respectively, much lower than those observed. Inclusion of the ionic strength parameterisation for the $\mathrm{NO}_{2}+\mathrm{S}$ kinetics (case $\mathrm{C}$ ) increases the calculated rate of $\mathrm{SO}_{4}$ formation by two orders of magnitude (a factor of 96), with the calculated contribution of the $\mathrm{NO}_{2}$ pathway for $\mathrm{SO}_{4}$

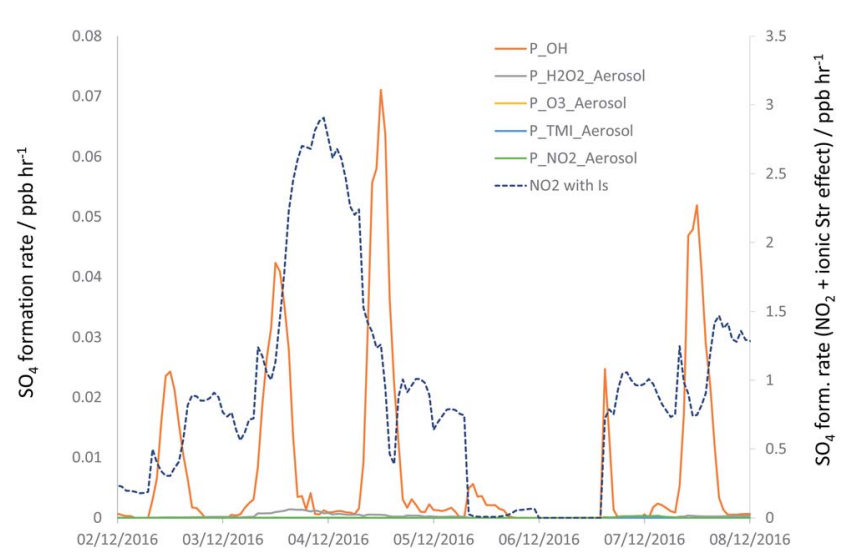

Fig. 6 Modelled $\mathrm{SO}_{4}$ formation rates (converted to $\mathrm{ppb} \mathrm{h}^{-1}$ ) through reaction of $\mathrm{SO}_{2}$ with $\mathrm{OH}$ (orange line), condensed phase reactions (all case B) with $\mathrm{H}_{2} \mathrm{O}_{2}$ (grey), $\mathrm{O}_{3}$ (yellow), transition metals (blue) and $\mathrm{NO}_{2}$ (green). Dashed line, second y axis: $\mathrm{NO}_{2}$ reaction considering impacts of ionic strength on $\mathrm{NO}_{2}+\mathrm{S}(\mathrm{IV})$ reaction kinetics (i.e. case C). See Fig. $\mathrm{S} 5$ (ESI $\uparrow$ ) for expansion of the $\mathrm{H}_{2} \mathrm{O}_{2}, \mathrm{O}_{3}$ and TMI timeseries. 
formation increasing to $98 \%$ overall, as a consequence of the very strong dependence or the rate constant upon ionic strength, highlighting this critical uncertainty in this aspect of the kinetics parameterisation. The average and maximum rates of $\mathrm{SO}_{4}$ formation calculated for case $\mathrm{C}$ were 3.5 and $12 \mu \mathrm{g} \mathrm{m}^{-3}$ $\mathrm{h}^{-1}$, respectively, comparable to the behaviour observed (Fig. 1 and S3 $\dagger$ ).

The timeseries for the modelled $\mathrm{SO}_{4}$ formation rates for each chemical mechanism under case (B), and for the $\mathrm{NO}_{2}$-driven processing under case (C), are shown in Fig. 6 for the 2-7 December focus period - note the different $y$ axis scale used for the latter data series (see also Fig. S4 $\dagger$ ). The significant increase in the overall rate of formation of $\mathrm{SO}_{4}$ for case (C) is in much closer accord with the rates of $\mathrm{SO}_{4}$ formation derived from the observed timeseries (Fig. 1), than for cases (A) and (B).

Considering the rate of production of $\mathrm{NO}_{2}{ }^{-}$, as an estimate to the HONO formation rate associated with $\mathrm{NO}_{2} / \mathrm{SO}_{2}$ oxidation, it is clear that the non-ionicstrength enhanced kinetics (case (A) and (B) - the latter as show in Fig. 6) are too small to make any appreciable impact upon HONO production, compared with the dominant $\mathrm{OH}+\mathrm{NO}$ reaction flux. Calculated HONO formation from case (C), dominated by the ionic-strength-dependent reaction with $\mathrm{NO}_{2}$, was added to the homogeneous $\mathrm{OH}+\mathrm{NO}$ production to determine the impact upon calculated steady state HONO concentrations, according to eqn (E3), and as shown in Fig. 4 and 5 as HONO (+Model).

$$
\begin{aligned}
{[\mathrm{HONO}]=} & \left\{k_{1}[\mathrm{OH}][\mathrm{NO}]+\left[\text { Modelled } \mathrm{SO}_{2}+\mathrm{NO}_{2} \text { rate }\right]\right\} /\left\{k_{2}[\mathrm{OH}][\mathrm{HONO}]\right. \\
& \left.+j_{3}[\mathrm{HONO}]\right\}
\end{aligned}
$$

Addition of the $\mathrm{SO}_{2}+\mathrm{NO}_{2}$ derived HONO flux increases the HONO levels by $27 \%$ on average, and modestly improves agreement between the calculated and observed HONO levels $\left(r^{2}=0.98\right)$. The observed and PSS-calculated HONO levels are compared as a function of $\mathrm{SO}_{4}$ in Fig. $\mathrm{S} 3 \dagger-$ while higher levels of both are associated with more polluted conditions (more $\mathrm{PM}_{2.5}$, more $\mathrm{SO}_{4}$ ), no bias between the observed and PSS-calculated levels with respect to $\mathrm{SO}_{4}$ is apparent, indicating this factor is not dominant. By applying a scale factor to the modelderived HONO production component, it can be shown that the rate of $\mathrm{SO}_{2}$ oxidation by $\mathrm{NO}_{2}$, as simulated here, is consistent with the observed HONO within the scatter of the data, but would cease to be so if the ionic strength enhancement factor were to be significantly increased - an upper limit (corresponding to a regression gradient of 1.5) of a factor of 4.5 fold higher may be estimated.

\section{Conclusions}

Nitrous acid was measured in the urban atmosphere of Beijing, at mixing ratios of up to $10 \mathrm{ppb}$ (significantly higher than many other cities, e.g. $1.6 \mathrm{ppb}$ for London ${ }^{17}$ ). HONO abundance, alongside that of many air pollutant species, was correlated with the formation of episodic haze events, associated with rapid growth in $\mathrm{PM}_{2.5}$ under elevated $\mathrm{RH}$ conditions, including increases in sulphate concentration. The HONO abundance was correlated with that of $\mathrm{SO}_{4}$, and with $\mathrm{RH}$. The $\mathrm{HONO} / \mathrm{NO}_{2}$ ratio, a marker for heterogeneous interconversion of reactive nitrogen oxides to HONO through dark- and photo-enhanced reaction processes, 
was not correlated with aerosol abundance, indicating heterogeneous formation does not dominate HONO production. Rather, during daytime, fast conventional gas-phase chemistry - the $\mathrm{OH}+\mathrm{NO}$ reaction (2), and HONO photolysis (4) dominates the HONO abundance in wintertime Beijing, and considering these processes (and the minor $\mathrm{HONO}+\mathrm{OH}$ reaction (R3)), permits alone good quantitative agreement (regression coefficient $=0.90 \pm 0.38$ ) between measured and calculated photostationary steady state HONO levels.

Combination of observationally-constrained rates of HONO formation and loss through reactions (2)-(4), with the calculated rates of HONO production through heterogeneous mechanisms including $\mathrm{H}_{2} \mathrm{O}_{2}, \mathrm{O}_{3}$, transition metal and S$\mathrm{NO}_{2}$ chemistry showed that, discounting the effects of ionic strength, the condensed phase mechanisms made a negligible contribution to HONO formation, while $\mathrm{SO}_{2}$ oxidation was dominated by gas-phase $\mathrm{OH}$ chemistry, with the $\mathrm{S}-$ $\mathrm{NO}_{2}$ reaction contributing $1.6 \%$ of the total. Inclusion of the ionic strength effects, including parameterisation of the $\mathrm{NO}_{2}-\mathrm{S}$ (Iv) kinetics following Cheng et al., ${ }^{6}$ led to calculated condensed-phase nitrite production equivalent to increases in the steady state HONO levels of $27 \%$, modestly increasing agreement with the HONO levels observed. Under this scenario, the $\mathrm{NO}_{2}-\mathrm{S}$ processing dominates $\mathrm{SO}_{4}$ formation. Considering the constraint the HONO levels place upon the additional production attributable to the $\mathrm{NO}_{2}-\mathrm{S}$ reaction, an upper limit to the maximum possible enhancement of the ionic-strength-dependent kinetics of a factor of 4.5 is estimated.

This work demonstrates the potential, and limitations, for coordinated observations of gaseous and particulate atmospheric composition to constrain fundamental processes which are extremely challenging to evaluate accurately in the laboratory or field - in this case, aerosol liquid water $\mathrm{pH}$ and ionic strength kinetic behaviour under very strongly non-ideal conditions. A key limitation of the data which are available here is their fixed measurement location: a lagrangian approach, allowing parameters to be evaluated along the trajectory of an evolving airmass at higher altitude and remote from possible surface influence may facilitate greater insight.

\section{Conflicts of interest}

There are no conflicts of interest.

\section{Acknowledgements}

This work was funded by the UK Natural Environment Research Council (NERC), the Medical Research Council and Natural Science Foundation of China under the framework of the Newton Innovation Fund (NE/N007190/1 and NE/N007077/ 1), and by the UK NERC through the project Sources of Nitrous Acid in the Atmospheric Boundary Layer (SNAABL, NE/M013405/1). We acknowledge the support from Zifa Wang and Jie Li for hosting the APHH-Beijing campaign at IAP, and thank the whole APHH team for their support throughout the project campaigns in Beijing and beyond. 


\section{References}

1 B. Zheng, Q. Zhang, Y. Zhang, K. He, K. Wang, G. Zheng, F. Duan, Y. Ma and

T. Kimoto, Atmos. Chem. Phys., 2015, 15, 2031-2049.

2 O. Welz, J. D. Savee, D. L. Osborn, S. S. Vasu, C. J. Percival, D. E. Shallcross and C. A. Taatjes, Science, 2012, 335, 204.

3 T. Berndt, T. Jokinen, M. Sipilä, R. L. Mauldin III, H. Herrmann, F. Stratmann, H. Junninen and M. Kulmala, Atmos. Environ., 2014, 89, 603.

4 M. J. Newland, A. R. Rickard, L. Vereecken, A. Munoz, M. Rodenas and W. J. Bloss, Atmos. Chem. Phys., 2015, 15, 9521.

5 J. Wang, J. Li, J. Ye, J. Zhao, Y. Wu, J. Hu, D. Liu, D. Nie, F. Shen, X. Huang, D. D. Huang, D. Ji, X. Sun, W. Xu, J. Guo, S. Song, Y. Qin, P. Liu, J. R. Turner, H. C. Lee, S. Hwang, H. Liao, S. T. Martin, Q. Zhang, M. Chen, Y. Sun, X. Ge and D. J. Jacob, Nat. Commun., 2020, 11, 2844.

6 Y. Cheng, G. Zheng, C. Wei, Q. Mu, B. Zheng, Z. Wang, M. Gao, Q. Zhang, K. He, G. Carmichael, U. Poschl and H. Su, Sci. Adv., 2016, 2, e1601530.

7 M. Gao, G. R. Carmichael, Y. Wang, D. Ji, Z. Liu and Z. Wang, Front. Environ. Sci. Eng., 2016, 10, 16.

8 G. Wang, R. Zhang, M. E. Gomez, L. Yang, M. L. Zamora, M. Hu, Y. Lin, J. Peng, S. Guo and J. Meng, Proc. Natl. Acad. Sci. U. S. A., 2016, 113, 13630.

9 Y. Xie, A. Ding, W. Nie, H. Mao, X. Qi, X. Huang, Z. Xu, V. M. Kerminen, T. Petäjä, X. Chi, A. Virkkula, M. Boy, L. Xue, J. Guo, J. Sun, X. Yang, M. Kulmala and C. Fu, J. Geophys. Res., 2015, 120, 12679-12694.

10 R. Zhang, G. Wang, S. Guo, M. L. Zamora, Q. Ying, Y. Lin, W. Wany, M. Hu and Y. Wang, Chem. Rev., 2015, 115, 3803.

11 H. Guo, R. J. Weber and A. Nenes, Sci. Rep., 2017, 7, 12109.

12 J. Shao, Q. Chen, Y. Wang, X. Lu, P. He, Y. Sun, V. Shah, R. V. Martin, S. Philip, S. Song, Y. Zhao, Z. Xie, L. Zhang and B. Alexander, Atmos. Chem. Phys., 2019, 19, 6107-6123.

13 H.-M. Hung and M. R. Hoffmann, Environ. Sci. Technol., 2015, 49, 13768.

14 C. Ye, P. Liu, Z. Ma, C. Xue, C. Zhang, Y. Zhang, J. Liu, C. Liu, X. Sun and Y. Mu, Environ. Sci. Technol. Lett., 2018, 5, 757-763.

15 P. He, B. Alexander, L. Geng, X. Chi, S. Fan, H. Zhan, H. Kang, G. Zheng, Y. Cheng, H. Su, C. Liu and Z. Xie, Atmos. Chem. Phys., 2018, 8, 5515.

16 J. H. Seinfeld and S. N. Pandis, Atmospheric Chemistry and Physics: From Air Pollution to Climate Change, John Wiley \& Sons, Inc., Hoboken, New Jersey, 3rd edn, 2016.

17 J. D. Lee, L. K. Whalley, D. E. Heard, D. Stone, R. E. Dunmore, J. F. Hamilton, D. E. Young, J. D. Allan, S. Laufs and J. Kleffmann, Atmos. Chem. Phys., 2016, 16, 2747.

18 S. Kim, T. C. VandenBoer, C. J. Young, T. P. Riedel, J. A. Thornton, B. Swarthout, B. Sive, B. Lerner, J. B. Gilman, C. Warneke, J. M. Roberts, A. Guenther, N. L. Wagner, W. P. Dubé, E. Williams and S. S. Brown, J. Geophys. Res., 2014, 119, 6886-6896.

19 E. J. Slater, L. K. Whalley, R. Woodward-Massey, C. Ye, J. D Lee, F. Squires, J. R. Hopkins, R. E. Dunmore, M. Shaw, J. F. Hamilton, A. C. Lewis, L. R. Crilley, L. Kramer, W. Bloss, T. Vu, Y. Sun, W. Xu, S. Yue, L. Ren, 
W. J. F. Acton, C. N. Hewitt, X. Wang, P. Fu and D. E. Heard, Atmos. Chem. Phys. Discuss., 2020, DOI: 10.5194/acp-2020-362.

20 J. Kleffman, T. Gavriloaiei, A. Hofzumahaus, F. Holland, R. Koppmann, L. Rupp, E. Schosser, M. Siese and A. Wahner, Geophys. Res. Lett., 2005, 32, L05818.

21 R. Oswald, M. Ermel, K. Hens, A. Novelli, H. G. Ouwersloot, P. Paasonen, T. Petäjä, M. Sipilä, P. Keronen, J. Bäck, R. Königstedt, Z. Hosaynali Beygi, H. Fischer, B. Bohn, D. Kubistin, H. Harder, M. Martinez, J. Williams, T. Hoffmann, I. Trebs and M. Sörgel, Atmos. Chem. Phys., 2015, 15, 799.

22 X. Li, T. Brauers, R. Häseler, B. Bohn, H. Fuchs, A. Hofzumahaus, F. Holland, S. Lou, K. D. Lu, F. Rohrer, M. Hu, L. M. Zeng, Y. H. Zhang, R. M. Garland, H. Su, A. Nowak, A. Wiedensohler, N. Takegawa, M. Shao and A. Wahner, Atmos. Chem. Phys., 2012, 12, 1497.

23 B. H. Lee, E. C. Wood, S. C. Herndon, B. L. Lefer, W. T. Luke, W. H. Brune, D. D. Nelson, M. S. Zahniser and J. W. Munger, J. Geophys. Res., 2013, 118, 12274-12281.

24 L. R. Crilley, L. Kramer, F. D. Pope, L. K. Whalley, D. R. Dryer, D. E. Heard, J. D. Lee, C. Reed and W. J. Bloss, Faraday Discuss., 2016, 189, 191.

25 Y. Liang, Q. Zha, W. Wang, L. Cui, K. H. Lui, K. F. Ho, Z. Wang, S. C. Lee and T. Wang, J. Air Waste Manage. Assoc., 2017, 67, 797.

26 L. J. Kramer, L. R. Crilley, T. J. Adams, S. M. Ball, F. D. Pope and W. J. Bloss, Atmos. Chem. Phys., 2020, 20, 5231.

27 B. Weber, D. Wu, A. Tamm, N. Ruckteschler, E. Rodríguez-Caballero, J. Steinkamp, H. Meusel, W. Elbert, T. Behrendt, M. Sörgel, Y. Cheng, P. J. Crutzen, H. Su and U. Pöschl, Proc. Natl. Acad. Sci. U. S. A., 2015, 15, 15384.

28 H. Su, Y. Cheng, R. Oswald, T. Behrendt, I. Trebs, F. X. Meixner, M. O. Andreae, P. Cheng, Y. Zhang and U. Pöschl, Science, 2011, 333, 1616.

29 B. J. Finlayson-Pitts, L. M. Wingen, A. L. Sumner, D. Syomin and K. A. Ramazan, Phys. Chem. Chem. Phys., 2003, 5, 223.

30 C. George, R. S. Strekowski, J. Kleffmann, K. Stemmler and M. Ammann, Faraday Discuss., 2005, 130, 195.

31 J. Kleffmann, ChemPhysChem, 2007, 8, 1137.

32 F. Spataro and A. Ianniello, J. Air Waste Manage. Assoc., 2014, 64, 1232.

33 Z. Shi, T. Vu, S. Kotthaus, R. M. Harrison, S. Grimmond, S. Yue, T. Zhu, J. Lee, Y. Han, M. Demuzere, R. E. Dunmore, L. Ren, D. Liu, Y. Wang, O. Wild, J. Allan, W. J. Acton, J. Barlow, B. Barratt, D. Beddows, W. J. Bloss, G. Calzolai, D. Carruthers, D. C. Carslaw, Q. Chan, L. Chatzidiakou, Y. Chen, L. Crilley, H. Coe, T. Dai, R. Doherty, F. Duan, P. Fu, B. Ge, M. Ge, D. Guan, J. F. Hamilton, K. He, M. Heal, D. Heard, C. N. Hewitt, M. Hollaway, M. Hu, D. Ji, X. Jiang, R. Jones, M. Kalberer, F. J. Kelly, L. Kramer, B. Langford, C. Lin, A. C. Lewis, J. Li, W. Li, H. Liu, J. Liu, M. Loh, K. Lu, F. Lucarelli, G. Mann, G. McFiggans, M. R. Miller, G. Mills, P. Monks, E. Nemitz, B. Ouyang, P. I. Palmer, C. Percival, O. Popoola, C. Reeves, A. R. Rickard, L. Shao, G. Shi, D. Spracklen, D. Stevenson, Y. Sun, Z. Sun, S. Tao, S. Tong, Q. Wang, W. Wang, X. Wang, X. Wang, Z. Wang, L. Wei, L. Whalley, X. Wu, Z. Wu, P. Xie, F. Yang, Q. Zhang, Y. Zhang, Y. Zhang and M. Zheng, Atmos. Chem. Phys., 2019, 19, 7519.

34 J. Heland, J. Kleffmann, R. Kurtenbach and P. Wiesen, Environ. Sci. Technol., 2001, 35, 3207. 
35 J. Kleffmann, J. Heland, R. Kurtenbach, J. C. Lorzer and P. Wiesen, Environ. Sci. Pollut. Res., 2002, 9, 48.

36 J. Kleffmann and P. Wiesen, Atmos. Chem. Phys., 2005, 5, 77.

37 L. R. Crilley, L. J. Kramer, B. Ouyang, J. Duan, W. Zhang, S. Tong, M. Ge, K. Tang, M. Qin, P. Xie, M. D. Shaw, A. C. Lewis, A. Mehra, T. J. Bannan, S. D. Worrall, M. Priestley, A. Bacak, H. Coe, J. Allan, C. J. Percival, O. A. M. Popoola, R. L. Jones and W. J. Bloss, Atmos. Meas. Tech., 2019, 12, 6449.

38 J. Xu, S. Song, R. M. Harrison, C. Song, L. Wei, Q. Zhang, Y. Sun, L. Lei, C. Zhang, X. Yao, D. Chen, W. Li, M. Wu, H. Tian, L. Luo, S. Tong, W. Li, J. Wang, G. Shi, Y. Huangfu, Y. Tian, B. Ge, S. Su, C. Peng, Y. Chen, F. Yang, A. Mihajlidi-Zelić, D. Đorđević, S. J. Swift, I. Andrews, J. F. Hamilton, Y. Sun, A. Kramawijaya, J. Han, S. Saksakulkrai, C. Baldo, S. Hou, F. Zheng, K. R. Daellenbach, C. Yan, Y. Liu, M. Kulmala, P. Fu and Z. Shi, Atmos. Meas. Tech., 2020, DOI: 10.5194/amt-2020-156.

39 H. Du, J. Li, X. Chen, Z. Wang, Y. Sun, P. Fu, J. Li, J. Gau and Y. Wei, Atmos. Chem. Phys., 2019, 19, 9351.

40 R. A. Zaveri and L. K. Peters, J. Geophys. Res.: Atmos., 1999, D23, 30387.

41 C. Fountoukis and A. Nenes, Atmos. Chem. Phys., 2007, 7, 4639.

42 F. J. Millero, Mar. Chem., 1989, 28, 1. 